sibility of intrathymic metastasis rather than multicentric thymoma development. No other reports of multiple thymoma, however, have inferred that the origin was through intrathymic metastasis because of the small number of tumors, similar sizes, and noninvasiveness. ${ }^{2,3}$ This case was a triple thymoma with three different histologic types, and we suppose that these three tumors originated independently from different areas of the thymus, because the histopathologic types are classified according to the normal differentiation of the major functional and anatomic compartments of the thymus. ${ }^{7}$ Moreover, hyperplasia of thymic epithelial cells was seen in other thymic tissue of the specimen, although it is not known whether those lesions would grow into a thymoma. From these cases, we suspect that the thymus has a potential to develop multicentric thymomas.

Although we performed a total thymectomy in this case, the extent of the excision for thymoma is controversial even when complete resection is accomplished. Nevertheless, we think that a total thymectomy is the best approach to resection for thymoma because there may be multicentric thymomas.

\section{References}

1. Nomori H, Kobayashi K, Ishihara T, Suito T, Torikata C. A case of multiple thymoma: the possibility of intra-thymic metastasis. Jpn J Clin Oncol. 1990;20:209-11.

2. Nonami Y, Moriki T. Synchronous independent bifocal orthotopic thymomas. A case report. J Cardiovasc Surg (Torino). 2004;45:585-7.

3. Yoneda S, Matsuzoe D, Kawakami T, Tashiro Y, Shirahama H, Ohkubo $\mathrm{K}$, et al. Synchronous multicentric thymona: report of a case. Surg Today 2004;34:597-9.

4. Rosai J, Sobin LH. World Health Organization histological classification of tumours. Histological typing of tumours of the thymus. 2nd ed. Berlin-Heidelberg: Springer-Verlag; 1999.

5. Bernatz PE, Harrison EG, Clagett OT. Thymoma: a clinicopathologic study. J Thorac Cardiovasc Surg. 1961;42:424-44

6. Maggi G, Casadio C, Cavallo A, Cianci R, Molinatti M, Ruffini E. Thymoma: results of 241 operated cases. Ann Thorac Surg. 1991;51: 152-6.

7. Marino M, Müller-Hermelink HK. Thymoma and thymic carcinoma. Relation of thymoma epithelial cells to the cortical and medullary differentiation of thymus. Virchows Arch A Pathol Anat Histopathol. 1985;407:119-49.

\title{
Tracheal injury during pneumonectomy: Semi-conservative treatment
}

\author{
Salvatore Griffo, MD, ${ }^{\mathrm{a}}$ Paolo Stassano, MD, ${ }^{\mathrm{b}}$ Gaetano Fraioli, MD, ${ }^{\mathrm{a}}$ Mario Monaco, MD, ${ }^{\mathrm{b}}$ Marcellino Cicalese, $\mathrm{MD}^{\mathrm{a}}$

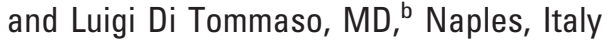

$\mathrm{T}$ racheobronchial laceration (TBL) is a serious lesion usually occurring during endotracheal intubation and frequently involving the pars membranacea. Treatment can be conservative for small lesions and when the patient's condition is stable, or surgical for bigger lesions and when pneumomediastinum and/or subcutaneous emphysema threaten the patient's life. ${ }^{1,2}$

We hereby describe a case of right-sided TBL in a patient undergoing left pneumonectomy in which a semi-conservative treatment was accomplished.

\section{Clinical Summary}

A 54-year-old, 156-cm tall male patient was admitted to our hospital with a diagnosis of squamous cancer of the left lung. The tumor was clinically staged as T2 N0 M0. General anesthesia was induced, and the patient was easily intubated with an endotracheal double-lumen tube. With the patient in the right lateral decubitus

From the Thoracic Surgery Department ${ }^{\mathrm{a}}$ and the Cardiac Surgery Department, ${ }^{\text {b } U n i v e r s i t y ~ F e d e r i c o ~ I I, ~ N a p l e s, ~ I t a l y . ~}$

Received for publication Aug 22, 2006; accepted for publication Oct 23, 2006.

Address for reprints: Salvatore Griffo, MD, Via Bausan, 1, 80121 Naples, Italy (E-mail: sal.griffo@libero.it).

J Thorac Cardiovasc Surg 2007;133:827-8

$0022-5223 / \$ 32.00$

Copyright $\odot 2007$ by The American Association for Thoracic Surgery

doi:10.1016/j.jtcvs.2006.10.040 position, through a lateral thoracotomy in the left fifth intercostal space, a left pneumonectomy was carried out. The left bronchus was doubly closed with mechanical and manual sutures and a drain was inserted. During the operation, the anesthesiologist did not report any episode of desaturation or bleeding from the tracheal tube. The patient was extubated on the table, his condition was stable, and blood gases were good.

Shortly after recovery from anesthesia, the patient suddenly began having intense dyspnea and a rapidly evolving subcutaneous emphysema in the head, neck, and upper part of the chest aggravated by coughing and without any air leak in the Bülau drainage. Blood gases were as follows: $\mathrm{PO}_{2} 38.8 \mathrm{~mm} \mathrm{Hg}, \mathrm{PCO}_{2} 34.1 \mathrm{~mm} \mathrm{Hg}$, $\mathrm{pH} 7.47$, and oxygen saturation $70 \%$. Chest radiography showed right pneumothorax and a wide pneumomediastinum. Examination with a fiberoptic bronchoscope revealed a tear (4-cm long) on the right side of the trachea $2 \mathrm{~cm}$ above the carina (Figure 1, A). The right pneumothorax was drained and the patient was returned to the operating room. We thought that performing a right thoracotomy in a patient with a left pneumonectomy and in respiratory distress would not be wise. Therefore, we decided to treat the patient semi-conservatively. With general anesthesia, we performed an anterior cervicotomy. The infrahyoid muscles were dissected, the pretracheal fascia was entered, and a drain was inserted into the pretracheal space (Figure 1,B).

The patient's clinical condition improved, the subcutaneous and mediastinal emphysema disappeared, the patient was extubated in the operating room, and the postoperative course was uneventful. Mediastinal and right chest drains were removed 3 and 5 days, respectively, after the operation, and the patient was 


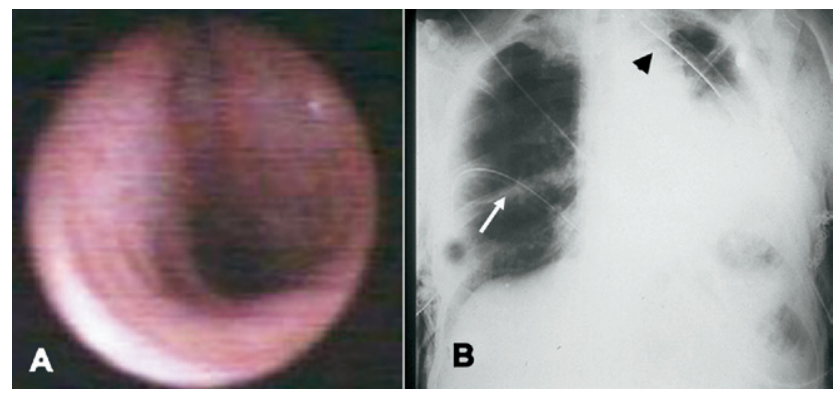

Figure 1. A, Fiberoptic broncoscope reveals a tear on the right side of the trachea. $B$, Chest radiography with a drain in the mediastinum (arrowhead) and a drain in the right side of the chest (arrow).

discharged to his home on the eighth postoperative day. A bronchoscopic examination, performed at day 30 after the tracheal lesion, showed perfect scarring. Two years later the patient is in good clinical condition and without recurrence of the squamous tumor (Figure 2).

\section{Discussion}

Tracheobronchial lacerations are rare complications of endotracheal intubation. Frequency of TBL after double-lumen intubation is less than $1 \% .^{3}$ Female sex, shortness of stature, difficult intubation, and abnormalities and weakness of the membranous trachea (eg, elderly patients, steroid therapy) are predisposing factors. $^{2}$ Inadequate tube size, overdistention of the cuff, sudden movements and malpositioning of the tube, and repeated attempts at intubation are the main factors causing these lacerations. ${ }^{4}$ Symptoms may appear during mechanical ventilation (desaturation, bleeding from the tube, mediastinal emphysema) or after the mechanical ventilation has been stopped and the patient resumes normal breathing and coughing (subcutaneous emphysema, dyspnea, pneumomediastinum, hemoptysis). ${ }^{4}$ Examination with a fiberoptic bronchoscope, with adequate sedation to avoid coughing, is mandatory in establishing the diagnosis.

Treatment can be conservative or aggressive depending on the extension of the lesion and patient's clinical condition. Usually, conservative treatment is preferred for stable patients with small uncomplicated tracheobronchial lesions, although conservative treatment has been described for a 7 -cm-long lesion. ${ }^{5}$ Surgical treatment (through a standard thoracothomy or transcervical approach) is reserved for patients requiring mechanical ventilatory support, for patients after thoracic surgical procedures, for unstable patients with pneumomediastinum, and for emphysema involving the chest, neck, and face. ${ }^{1,3}$ Surgery offers prompt repair, avoids

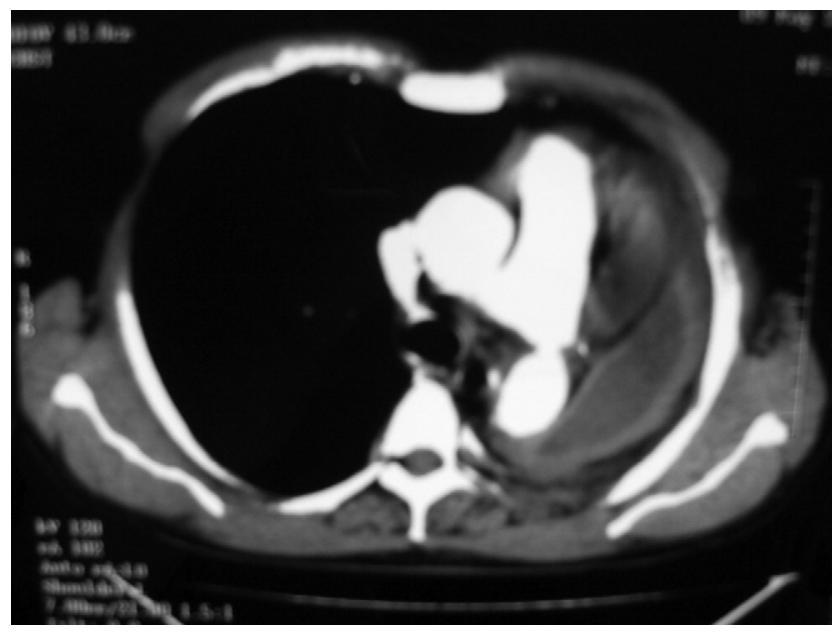

Figure 2. Computed tomographic scan of the chest showing no recurrence of the tumor 2 years later.

complications (descendent mediastinitis) and sequelae (tracheal stenosis), and allows a relatively short recovery time.

In our case we were caught in a very difficult situation. On the one hand, we had a right tracheal lesion, huge emphysema of the neck and face, pneumomediastinum, right pneumothorax, respiratory distress, and occurrence of the lesion after a thoracic surgical procedure: these factors all recommended an immediate surgical solution. On the other hand, we were worried about performing a right thoracotomy after a left pneumonectomy in a very unstable patient.

Therefore, a semi-conservative treatment, drainage of the pneumothorax and an anterior cervicotomy with tube insertion, avoiding direct surgical closure, appeared to be the best option.

\section{References}

1. Lancelin C, Chapelier AR, Fadel E, Macchiarini P, Dartevelle PG. Transcervical-transtracheal endoluminal repair of membranous tracheal disruptions. Ann Thorac Surg. 2000;70:984-6.

2. Carbognani P, Bobbio A, Catellani L, Internullo E, Caporale D, Rusca M. Management of postintubation membranous tracheal rupture. Ann Thorac Surg. 2004;77:406-9.

3. Jougon J, Ballester M, Choukroun E, Dubrez J, Reboul G, Velly J. Conservative treatment for postintubation tracheobronchial rupture. Ann Thorac Surg. 2000;69:216-20.

4. Mussi A, Ambrogi MC, Menconi G, Ribechini A, Angeletti CA. Surgical approaches to membranous tracheal wall lacerations. J Thorac Cardiovasc Surg. 2000;120:115-8.

5. Mercadante E, Giovannini C, Castaldi F, Dell'Avanzato R, Zazza S, Andreozzi G, et al. Major iatrogenic tracheal injury during pneumonectomy: conservative treatment. Ann Thorac Surg. 2006;81:2285-7. 